\title{
Urea-Formaldehyde Microcapsules for Insects Repellent purposes
}

\author{
Karuppasamy Karpagalakshmi, R. Sathish Kannan, Narayanan Selvapalam, Ramesh Prakash, \\ Lakshminarayanan Piramuthu
}

\begin{abstract}
Microcapsules are the material of choice for several applications that include pharmaceutical products, insulation technology, food preservation, personal care products and many more. Urea-formaldehyde polymers can be converted to microcapsules by oil-water emulsion method. Microcapsules were characterized by optical microscope, FTIR and SEM. Microcapsules can encapsulate the dyes and mosquito repellant, which can be released slowly under different conditions. The release studies indicate that the microcapsules can be used as a slow release of mosquito repellant, especially for the domestic purposes.
\end{abstract}

Keywords: Urea-formaldehyde, polymer, Microcapsules, Slow release of drugs

\section{INTRODUCTION}

$\mathrm{M}_{\mathrm{i}}$ icrocapsules were created for useful applications due to their intrinsic properties. Microcapsules are the combination of holding two phase materials together in a shell like outer phase solid material, which can hold the gaseous or liquid phase materials inside microcapsules [1]. Volatile and highly reactive materials and gaseous products need the protection to prevent their reaction with the environment or the substrates. Such materials have been used in aerospace and construction materials, in which generation of crack is inevitable and microcapsules are the choice of material to solve these issues [2], [3]. The surface of the microcapsules is the key factor, which determines the strength and stability of the microcapsules under various environments [4]. When the epoxy materials are included inside the microcapsules, they can be used for self-healing material and some of the polymeric materials have been included for repairing purposes [5], [6]. To increase the durability of the materials, often cracks and defective portions should be repaired to

Revised Manuscript Received on December 15, 2019.

* Correspondence Author

Karuppasamy Karpagalakshmi Center for Supramolecular Chemistry, IRC and Department of Chemistry, Kalasalingam Academy of Research and Education, Krishnankoil 626126, India.n.selvapalam@klu.ac.in

R. Sathish Kannan Center for Supramolecular Chemistry, IRC and Department of Chemistry, Kalasalingam Academy of Research and Education, Krishnankoil 626126, India. n.selvapalam@klu.ac.in

Narayanan Selvapalam*, Center for Supramolecular Chemistry, IRC and Department of Chemistry, Kalasalingam Academy of Research and Education, Krishnankoil 626126, India. n.selvapalam@klu.ac.in

Ramesh Prakash, , IRC and Department of Chemistry, Kalasalingam Academy of Research and Education, Krishnankoil 626126, India.

Lakshminarayanan Piramuthu, , IRC and Department of Chemistry, Kalasalingam Academy of Research and Education, Krishnankoil 626126, India. maintain the stability of the materials without compromising the performance of the engine/materials [7].

Microcapsules have been intensively studied in many areas of research that include pharmaceutical [8], [9], slow release of fragrances [10], [11], electronic paper or e-paper [12], targeted drug delivery in biotechnological applications [13], [14], catalysts on demand for organic and inorganic reactions [15] and many others. In aerospace applications, cracks and defects are the major issues, which can be solved by the usage of microcapsules [7], [16].

Microcapsules have been majorly employed in the area of biotechnology for the stimuli-responsive healable materials [17]. For example, White et. al. have utilized the urea-formaldehyde microcapsules for the self-healing purposes using dicyclopenta-diene (DCPD), which can repair by the self polymerization of this epoxy material. DPCD can be used for repairing purposes through the cross polymerization by the metal catalysts, that include the important organometallic catalyst such as Grubbs'catalyst [18], [19]. For example, linseed oil has been filled in the urea-formaldehyde microcapsules and explored for the application of self-healing property on the cracked surfaces. Similarly, urea formaldehyde polymer based microcapsules have been explored in several applications through the inclusion of various materials inside the microcapsules. Formaldehyde could be used for good cross linking material for the making of microcapsules. Similar to the urea formaldehyde polymer microcapsules that encapsulated with epoxy resins [20], [21], [22], [23], melamine formaldehyde also encapsulated the epoxy resin [24], [26] and also included other curing agent [27]. In a similar way, polyurethane has been used in the microcapsules to obtain the strong shell wall materials for the applications which required self-healing properties [28], [29].

Since urea formaldehyde has been employed in extended applications of microcapsules, we decided to use this material for the making of microcapsules with mosquito repellent property. Until now, in India and other south east nations, mosquito repellent has been used in the form of liquid evaporator; through which the mosquito repellent material can be vaporized. N,N-Diethyl-meta-toluamide (DEET) Cyfluthrin, Permethrin, Pyrethroidsis are the chemicals that are commonly used in the mosquito repellent in the form of liquid along with low boiling essential oil, which slowly evaporated along with the toxic chemicals. We decided to use the urea formaldehyde microcapsules to encapsulate the commercial mosquito repellent to check the slow release of the repellent for the use of domestic purpose. 
Here, we report the various synthesis of microcapsules and encapsulation of dyes and mosquito repellent and finally examined the activity of mosquito repellent encapsulated microcapsules with the ants instead of mosquito.

\section{EXPERIMENTAL SECTION}

Urea $(97 \%)$; formaldehyde $(37 \%)$; sodium dodecyl sulfate (SDS) and triethylamine (TEA) were purchased from AVRA chemicals and commercial grade coconut oil and mosquito repellant were used in this study.

\section{Preparation of urea formaldehyde pre-polymer}

Urea formaldehyde pre-polymer was prepared by the addition of formaldehyde $(6.2 \mathrm{~mL}, 37 \%$ solution $)$ to the urea $(2.5 \mathrm{~g}$, $97 \%$ ) in a $250 \mathrm{~mL}$ round bottom flask and the $\mathrm{pH}$ of the solution was adjusted to 8 by the addition of triethylamine. This mixture was heated at $70^{\circ} \mathrm{C}$ for an hour to get the gel like materials, which is the pre-polymer of urea formaldehyde resin.

\section{Synthesis of microcapsules}

Microcapsules were synthesized according to the modified procedure of Guozheng Liang et. al [20]. The oil-water emulsion was prepared using SDS (0.2 g) and coconut oil (10 $\mathrm{mL})$ in DI water $(200 \mathrm{~mL})$ and stirred at $600 \mathrm{rpm}$ for the duration of $20 \mathrm{~min}$. To this, pre-polymer gel and ammonium chloride $(250 \mathrm{mg}$ ) were added and stirred it for $1 \mathrm{hr}$. To this formaldehyde $(2 \mathrm{~mL})$ was added and adjusted the $\mathrm{pH}$ to 2 by the addition of $\mathrm{HCl}$ and stirred at $65^{\circ} \mathrm{C}$ for $2 \mathrm{~h}$. At the end of the reaction, it appeared like a cloudy solution. This reaction mixture was cooled slowly to the room temperature and kept undisturbed for $12 \mathrm{~h}$ and it formed two layered product and the solid product was filtered and washed with water and re-dissolved in water for characterization of the microcapsules.

\section{Synthesis of rhodamine B encapsulated microcapsules}

The oil-water emulsion was prepared with rhodamine B using SDS (0.2 g), rhodamine B (2 mL) and coconut oil (10 mL) in DI water $(200 \mathrm{~mL})$ and stirred at $600 \mathrm{rpm}$ for the duration of 20 min. To this, pre-polymer gel and ammonium chloride $(250 \mathrm{mg}$ ) were added and stirred it for $1 \mathrm{hr}$. To this formaldehyde $(2 \mathrm{~mL})$ was added and adjusted the $\mathrm{pH}$ to 2 by the addition of $\mathrm{HCl}$ and stirred at $65^{\circ} \mathrm{C}$ for $2 \mathrm{~h}$. We followed the routine procedure to isolate the product as given earlier.

\section{Effect of poly (vinyl alcohol) with microcapsules}

The oil-water emulsion was prepared using SDS (0.2 g), poly (vinyl alcohol) $(250 \mathrm{mg}$ ) and coconut oil $(10 \mathrm{~mL})$ in DI water $(200 \mathrm{~mL})$ and stirred at $600 \mathrm{rpm}$ for the duration of $20 \mathrm{~min}$. To this, prepolymer gel and ammonium chloride $(250 \mathrm{mg})$ were added and stirred it for $1 \mathrm{hr}$. To this formaldehyde $(2 \mathrm{~mL})$ was added and adjusted the $\mathrm{pH}$ to 2 by the addition of $\mathrm{HCl}$ and stirred at $65^{\circ} \mathrm{C}$ for $2 \mathrm{~h}$. After the reaction, we followed routine procedure and isolated the product.

Synthesis of mosquito repellent included microcapsules
The oil-water emulsion was prepared with mosquito repellent using SDS $(0.2 \mathrm{~g})$, commercial mosquito repellent $(2 \mathrm{~mL})$ and coconut oil $(10 \mathrm{~mL})$ in DI water $(200 \mathrm{~mL})$ and stirred at 600 $\mathrm{rpm}$ for the duration of $20 \mathrm{~min}$. To this, pre-polymer gel and ammonium chloride $(250 \mathrm{mg}$ ) were added and stirred it for 1 $\mathrm{hr}$. To this formaldehyde $(2 \mathrm{~mL})$ was added and adjusted the $\mathrm{pH}$ to 2 by the addition of $\mathrm{HCl}$ and stirred at $65^{\circ} \mathrm{C}$ for $2 \mathrm{~h}$. We followed the routine procedure to isolate the product as given earlier.

\section{RESULTS AND DISCUSSION}

We carried out the synthesis of microcapsules based on the reported procedure [20]. We have modified the procedure as given in the experimental section. To synthesize the microcapsules, we have prepared the urea-formaldehyde pre-polymer. For that, urea was made reaction with the formaldehyde in water by adjusting the $\mathrm{pH}$ by 8 using triethylamine. The reaction mixture was heated at $70^{\circ} \mathrm{C}$ and it formed a gel like material, which is the intermediate product of the urea formaldehyde. This is the material, which get polymerized further with the oil-water emulsion material. So, we prepared the oil-water emulsion using the mixture of SDS, coconut oil and water. The purpose of SDS is to make the emulsion with water. When the oil was mixed with water and stirred at high speed, it produced as many as small droplets, which generally reassembled back to the oily layer; however, by the addition of SDS to it, forms large number of bubbles and thus the combination of SDS, oil and water produced the semi-stable micrometer sized bubbles. To that urea formaldehyde pre-polymer was added and furthermore ammonium chloride was also added to form the cross linked polymer of 3D network. To make the strong three dimensional networks, we have added both formaldehyde and ammonium chloride to the water-oil emulsion, in which ammonium chloride acted as a source of ammonia, which underwent condensation reaction with urea formaldehyde pre-polymer utilizing the formaldehyde that we added. The reaction was heated at $65^{\circ} \mathrm{C}$ for $2 \mathrm{~h}$ to make a homogenous but turbid solution, which was cooled to room temperature slowly for the duration of $12 \mathrm{~h}$. Subsequently, it formed a cake like material at the top, which was settled with the water. This cake like solid material was separated by Buckner funnel to separate the oil and un-reacted starting material and then the product was re-dissolved in water. The appearance of the microcapsules has been similar to the reported procedure[20]. In a similar way, we have also produced the rhodamine $B$ encapsulated microcapsules, For that purpose, we used the mixture SDS $(0.2 \mathrm{~g})$, rhodamine $\mathrm{B}(2 \mathrm{~mL})$ and coconut oil (10 $\mathrm{mL})$ in DI water $(200 \mathrm{~mL})$, which rendered the oil-water emulsion; in which rhodamine encapsulated micro-bubbles was formed. To that urea formaldehyde pre-polymer, ammonium chloride and formaldehyde were added to get the rhodamine encapsulated microcapsules upon heating it at 65 ${ }^{\circ} \mathrm{C}$ for $2 \mathrm{~h}$. As mentioned previously, these microcapsules were filtered and washed with DI water and finally re-dissolved in DI water. Poly(vinyl alcohol) (PVA) is a polymer, which can strengthen the microcapsules and thus we also prepared the microcapsules with the use of PVA as reported by Qixin Zhou et.al

[21]. 


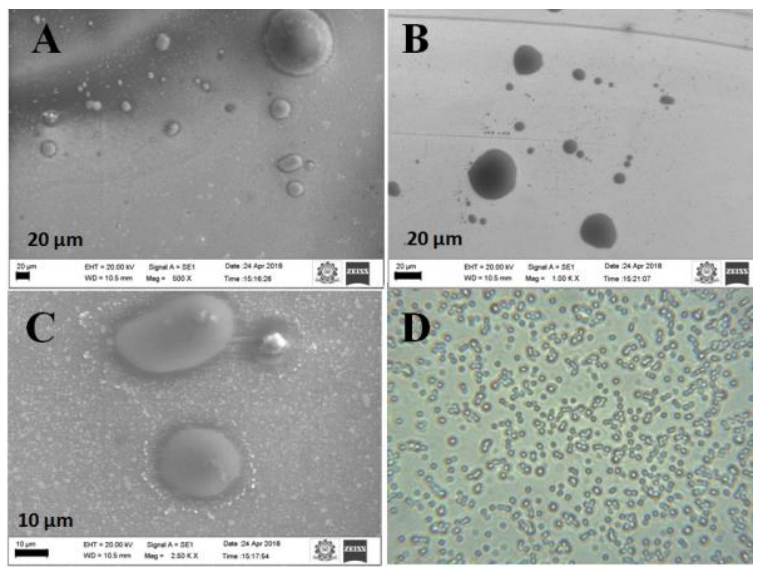

Fig. 1. (A-C) SEM images of microcapsules at different magnifications; (D) Optical microscope image of rhodamine B encapsulated microcapsules

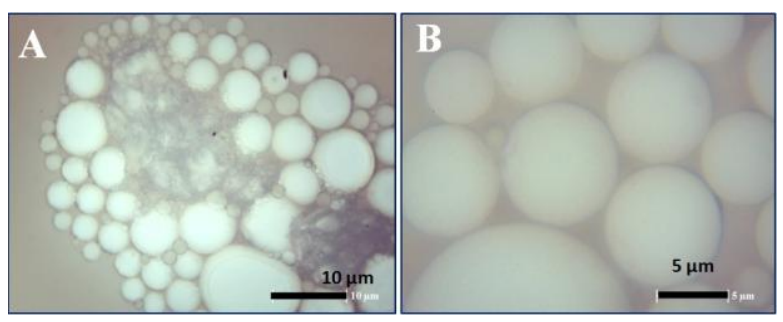

Fig. 2. Optical microscopic images of microcapsules with PVA as additive to strengthen the microcapsules

For that purpose, oil-water emulsion was prepared using SDS (0.2 g), poly (vinyl alcohol) $(250 \mathrm{mg})$ and coconut oil $(10 \mathrm{~mL})$ in DI water $(200 \mathrm{~mL})$ and stirred at $600 \mathrm{rpm}$. To that urea formaldehyde pre-polymer, ammonium chloride, and formaldehyde were added and heated at $65^{\circ} \mathrm{C}$ for $2 \mathrm{~h}$. They formed the microcapsules, which were filtered and isolated the product. We have examined the microcapsules using optical microscope, SEM and FTIR. As shown in Fig. 1 A-C, the SEM images taken for the microcapsules formed distorted spherical images. The distorted spherical images are due to the surface tension of the microcapsules, which experienced upon drying. When we examined these microcapsules by the optical microscope, the rhodamine B encapsulated microcapsules (Fig. 1D), initially it appeared perfect spherical in shape, which slowly deformed to distorted shape upon evaporation of the surrounded liquid. To solve this issue, we decided to add the PVA to make the robust microcapsules. As shown in fig. 2. PVA made the microcapsules with better strength; however, it also broke when it was allowed to evaporate at the room temperature. When the microcapsules were encapsulated with the rhodamine $\mathrm{B}$, it could store the rhodamine $\mathrm{B}$ within the available space provided by the microcapsules. Furthermore, the presence of rhodamine $\mathrm{B}$ inside the microcapsules was confirmed by the analysis of FTIR. As shown in fig. 3b, microcapsule without rhodamine B displayed no significance peaks of rhodamine B. However, the FTIR of rhodamine B encapsulated microcapsule (fig. 3c) displayed the significant peaks of rhodamine B such as $1556 \mathrm{~cm}^{-1}, 1257 \mathrm{~cm}^{-1}$ and 1029 $\mathrm{cm}^{-1}$. From that we could confirm the encapsulation of rhodamine $\mathrm{B}$ inside the microcapsule.

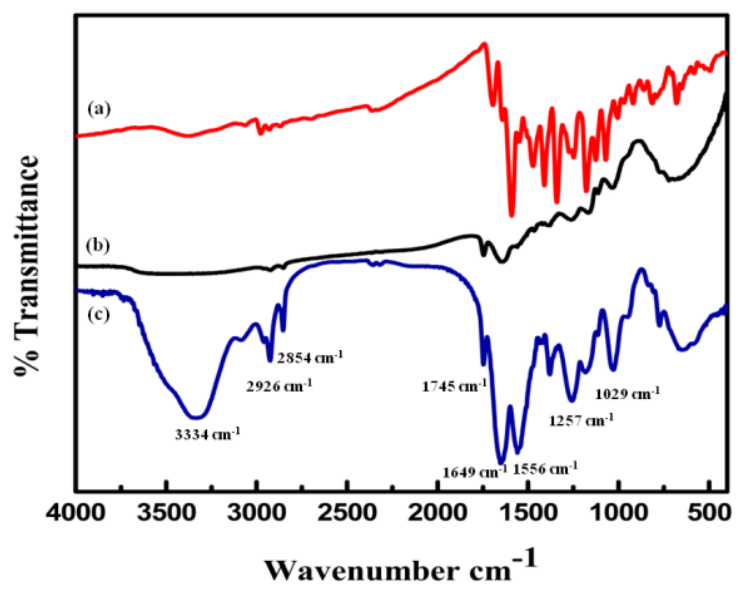

Fig. 3. FTIR spectrum of (a) rhodamine B (b) microcapsule without rhodamine $B$; (c) rhdoamine encapsulated microcapsules

To confirm the process of encapsulation, we have studied the release of rhodamine $\mathrm{B}$ from the microcapsules under different conditions. Finally, we found that the leaching can be done with the help of sonicator and by the organic solvent such as ethanol, acetone, DMF and DMSO. A portion of the microcapsule was taken in the centrifuge tube and to that organic solvent was added and sonicated it for the duration of $10 \mathrm{~min}$. The encapsulated rhodamine B slowly released from the microcapsule, which can be observed conveniently (Fig. 4). Under the UV light (365 nm), it also displayed the

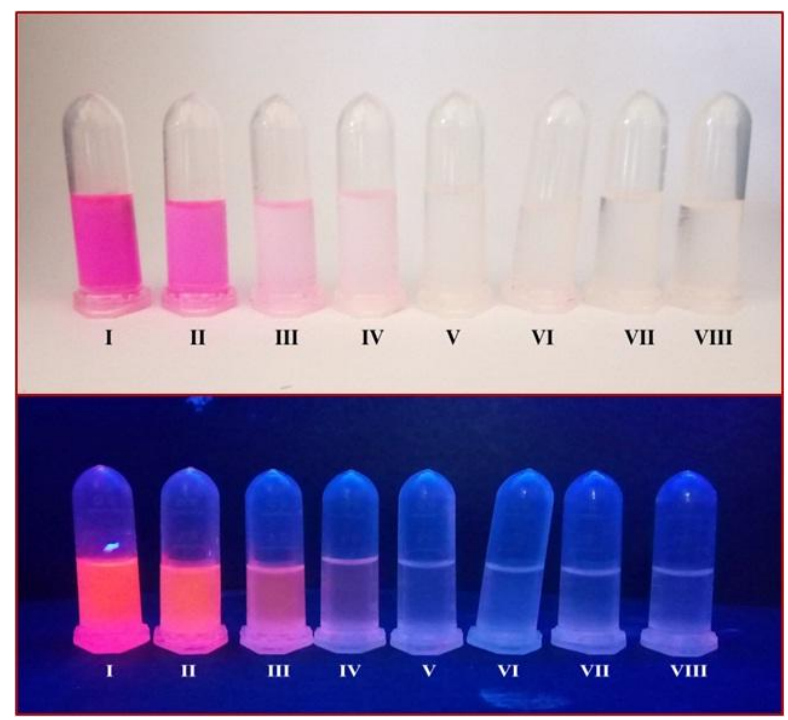

Fig. 4. Slow release studies of rhodamine $B$ from the microcansule that have encapsulated the dve molecule

fluorescence to assure the slow release of the rhodamine B upn treatment with organic solvent and sonication. Without sonication, the release of dye was slow down and thus we decided to use organic solvent and they can be used for various applications. To assure the application of these microcapsules, we have encapsulated domestically useful material such as mosquito repelling compounds and examined its extendibility to some of the interesting applications. 


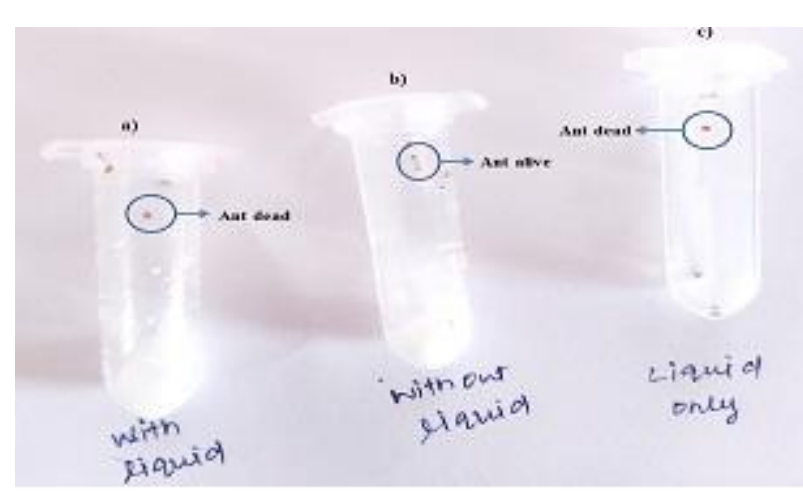

Fig. 5. (a) Microcapsules with mosquito repellent destroyed the ant; (b) Ant survived with the microcapsules having no mosquito repellent; (c) Mosquito repellent alone killed the

For that purpose, commercial mosquito repellent $(2 \mathrm{~mL})$, SDS $(200 \mathrm{mg})$, and coconut oil $(10 \mathrm{~mL})$ were taken in DI water $(200 \mathrm{~mL})$ and prepared the oil-emulsion. To that ammonium chloride $(250 \mathrm{mg})$ and formaldehyde $(2 \mathrm{~mL})$ and prepared the mosquito repellent encapsulated microcapsules by heating them at $65^{\circ} \mathrm{C}$ for $2 \mathrm{~h}$. The microcapsules were filtered and washed with water and used further for the application. To test the efficiency of this material, we have used ants instead of mosquito. As shown in fig.5. the ants survived when the normal microcapsules (fig. 5b) were added and the ants died when the mosquito repellent encapsulated microcapsules (fig. 5c) were added. In a similar way, ant was dead in the vial containing mosquito repellent alone. All these observation indicates that these microcapsules can be used for the domestic purpose with no additional equipments such as sprayer and electronic equipments. Besides, it is easy to store for a long duration, because the repellent will not be released unless it is allowed to expose to the external environments.

\section{CONCLUSION}

Overall, we have synthesized microcapsules using urea-formaldehyde polymers through the formation of oil-water emulsion method. These microcapsules were characterized by optical microscope, FTIR and SEM. We have prepared three different types of microcapsules that include microcapsules having no material inside, microcapsules encapsulated with rhodamine B dye material and microcapsules with mosquito repellent products. Besides, we have prepared the microcapsules with PVA and obtained robust microcapsules. Among them rhodamine B encapsulated microcapsules were utilized to demonstrate the slow release of core material from the microcapsules. The release studies intrigued us to prepare the mosquito repellant encapsulated microcapsules for the domestic purposes to destroy the harmful mosquitoes.

\section{ACKNOWLEDGMENT}

This work is financially supported by DST- SERB, India under Early Career Research Award (ECR/2015/000318). R. $\mathrm{P}$ and $\mathrm{K}$. $\mathrm{K}$ thanks to KARE for offering University $\mathrm{PhD}$ fellowship. All authors thank to the KARE for the facility offered to the M.Sc. students to perform the experiments.

\section{REFERENCES}

1. T. Siva, S. Sathiyanarayanan, "Self healing coating containing dual active agent loaded urea formaldehyde microcapsules" Progress in Organnic Coating, vol. 82, May 2015, .pp. 57-67.

2. S. R. White, N. R. Scottos, P. H. Geubelle, J. S. Moore, M. R. Kessler, S. R. Sriram, et.al., "Autonomic healing of polymer composites" Nature, vol. 409, February 2001, pp. 794-797.

3. M. R. Kessler, "Self-healing: a new paradigm in materials design" $J$. Aerospace Eng, vol. 221, April 2007, pp. 479.

4. L. Yuan, G. Liang, and J. Xie, " Synthesis and characterization of microcapsulated diclopentadiene with melamine formaldehyde resins" Colloid and Polymer Science, vol. 285, April 2007, pp. 781-791.

5. S. V. D. Zwaag, A. J. M. Schmets, and G. V. D. M. Zaken, “ International conference on selfhealing, in: Self healing materials an alternative approach to 20 centuries of materials science" Springer, the Netherlands, 2007.

6. S. K. Ghosh, "Self-healing materials: fundamentals, design strategies and appli-cations" Wiley-VCH, Weinheim, Chichester, 2009.

7. E. Brown, M. Kessler, N. Sottos, S. White, "In situ poly (urea-formaldehyde)microencapsulation of dicyclopentadiene", $J$ Microencapsul, vol. 20, May 2003, .pp. 719-730.

8. J. Eukaszczyk, P. Urba, "Influence of the parameters of encapsulation process and of the structure of diisocyanates on the release of codeine from resinate encapsulated in polyurea by interfacial water promoted polyreaction" React. Funct. Polym, vol. 33, August 1997, .pp. 233-239.

9. W. Tiyaboonchai, G. C. Ritthidej, "Development of indomethacin sustainedrelease microcapsules using chitosan-carboxy methyl-cellulose complex coacervation" J. Sci. Technol, vol. 25, May 2003, pp. 245-254

10. B. J. Park, J. Y. Lee, and J. H. Sung "Microcapsules containing electrophoretic suspension of $\mathrm{TiO} 2$ modified with poly (methyl methacrylate)" Appl Phys, vol. 6, July 2006,.pp. 632-635.

11. D. Saihi, I. Vroman, and S. Girand, "Microencapsulation of ammoniumphosphate with a polyurethane shell. Part II. Interfacial polymerization technique" React. Funct. Polym, vol. 64, September 2005,.pp. 127-138.

12. S. Girand ,S. Bourbigot , and M. Rochery "Flame retarded polyurea with microencapsulated ammonium phosphate for textile coating" Polym. Degrad. Stabil,vol. 88, April 2005, .pp. 106-113,

13. G. Orive, R. M. Hernandez, and A. R. Gascon, " Encapsulated cell technology: From research to market. Trends Biotechnol, vol. 20, January 2003, pp.382-387,

14. G. Sukhorukov, A.Fery , and H. Möhwald "Intelligent micro- and nanocapsules" Prog Polym Sci, vol. 30, August 2005,.pp. 885-897.

15. H. B. Ji, G. J. Kuang, and Y. Qian, "Development of an immobilization method by encapsulating inorganic metal salts forming hollow microcapsules" Catal Today, vol. 105, August 2005, pp. 605-611.

16. S. V. Lamaka, M. L. Zheludkevich,and K. A. Yasakau, "TiO self-assembled networks prepared by templating approach as nanostructured reservoirs for self-healing anticorrosion pre-treatments" Electrochem. Commun, vol. 8, March 2006, .pp 421-428.

17. E. B. Murphy, F. Wudl, “ The world of smart healable materials" Prog. Polym. Sci. vol.35, February 2010, pp. 223-251,

18. D. Y. Wu, S. Meure, and D. Solomon, "Self-healing polymeric materials: a review ofrecent developments" Prog. Polym. Sci. vol. 33 , May 2008, pp. 479-522.

19. J. D. Rule, E. N. Brown, N. R. Sottos, S. R. White, and J. S. Moore "Wax protected cat-alyst microspheres for efficient self healing materials," Adv. Mater. Vol. 17, January 2005, .pp. 205-208.

20. L. Yuan, G. Liang, J. Q. Xie, and L. Li, "Preparation and characterization of poly(urea-formaldehyde) microcapsules filled with epoxy resins" Polymer, vol. 47, July 2006,.pp. 5338-5349.

21. S. Lang, Q. Zhou, "Synthesis and characterization of poly(urea-formaldehyde) microcapsules containing linseed oil for self-healing coating development" Progress in Organic Coatings, vol. 105 pp. April 2017, pp..99-110.

22. S.Cosco, V. Ambrogi, and P. Musto, "Properties of poly (urea formaldehyde) microcapsules containing an epoxy resin" J. Appl. Polym. Sci, vol. 105, April 2007, pp. 1400-1411.

23. L. Yuan, G. Z. Liang,J. Q. Xie, J. Guo, and L. Li "Thermal stability of microencapsulated epoxy resins with poly (urea-formaldehyde)" Polym. Degrad. Stabil, vol. 91, October 2006, pp. 2300-2306, 
24. Y. C. Yuan, M. Z. Rong, and M. Q. Zhang, "Preparation and characterization of poly (melamine-formaldehyde) walled microcapsules containing epoxy" Acta. Poly. Sin, vol. 5, September 2008, .pp. 472-480.

25. Y. C. Yuan, M. Z. Rong, and M. Q. Zhang, "Self-healing polymeric materials using epoxy/mercaptan as the healant" Macromolecules, vol. 41, June 2008, pp. 5197-5202.

26. T. Yin , M. Z. Rong, M.Q. Zhang, and G. C.Yang, "Self-healing epoxy composites-preparation and effect of the healant consisting of microencapsulated epoxy and latent curing agent" Compos. Sci. Technol. Vol. 67, February 2007, pp. 201-212.

27. Y. C. Yuan, M. Z. Rong , and M.Q. Zhang, "Preparation and characterization of microencapsulated polythiol. Polymer, vol. 49, May 2008, pp. 2531-2541,

28. J. Yang, M. W. Keller, S. R. White, N. R. Sottos "Microencapsulation of isocyanates for self-healing polymers" Macromolecules, vol. 41, November 2008, .pp. 9650-9655.

29. M. Behzadnasaba, M. Esfandeha, S. M. Mirabedinia, and R. R. Farnood, "Preparation and characterization of linseed oil-filled urea-formaldehyde microcapsules and their effect on mechanicalproperties of an epoxy-based coating" Physicochem. Eng. Aspects, vol. 457, May 2014, pp. 16-26.

\section{AUTHORS PROFILE}

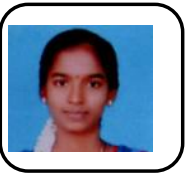

Karpagalakshmi karuppasamy. was born in sivakasi, Tamilnadu in 1993. She received her M.. Sc. degree from the Madurai Kamaraj University, Madurai, in 2016 and obtained her B. Sc degree in 2014 from, Madurai Kamaraj University, Madurai. She has started her Ph. D. studies in 2016 under the supervision of Dr. N. Selvapalam at kalasalingam academy of Research and Education, Krishnankoil, India. Her research interests are in the area of organic synthesis, nano-materials and supramolecular chemistry

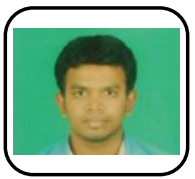

R.Sathishkannan born in Virudhunagar,Tamilnadu in 1995. He received his M.Sc degree from Kalasalingam Academy of Research And Education, Krishnan Koil, Virudhunagar District in 2017. He joined Ph.D under the supervision of Dr.B.Sundaravel at Kalasalingam Academy of Research And Education, Krishnan Koil, Virudhunagar District in 2019. His research interest is on the area of functional material for Catalytic, Energy and Sensor application.

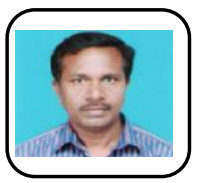

Dr. Narayanan Selvapalam received his M.S.and Ph.D degrees from Mysore University and IIT Delhi, respectively. He is presently working as Associate Professor at the Kalasalingam Academy of Research and Education (Kalasalingam University) His research interests include supramolecular chemistry, glycoluril based polymers, Chemistry of cucurbiturils and cyclodextrins, organic synthesis and sensors.

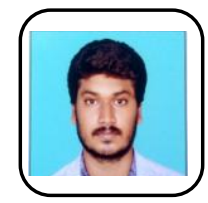

Ramesh Prakash born in Karur,Tamilnadu in 1991 He received his M.Phil degree from the BharathidasanUniversity, Trichy, in 2015 and obtained his MSc degree in 2014 at St. Joseph's College, Trichy. He joined Ph.D. in 2015 under the supervision of Dr. N. Selvapalam at Kalasalingam Academy of Research and Education inVirudhunagar district. He is awarded a direct-Senior Research Fellowship from CSIR in 2018 to till date. His research interest is on the area of nanomaterials synthesis and supramolecular chemistry.

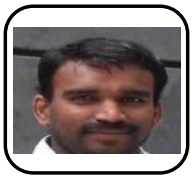

Dr. Lakshminarayanan Piramuthu was born in Kizhapuliyur, Tenkasi, India, in 1979. He studied Chemistry at Sri Paramakalyani College, Alwarkurichi, India. He obtained his Ph.D. degree in the area of Development of Receptors for Recognition of Halides and Water Clusters: Further Functionalization of Receptors with Fluorophoric Units from Indian Association for the Cultivation of Science
IACS, Kolkata under the direction of Professor Pradyut Ghosh. His basic focus is, to study the biologically relevant anion recognition and sensing of the synthetic receptors, he has also contributed to other areas such as crystal engineering and organic synthesis. 